\title{
EL DISFRAZ DE LA LOCURA Y LA SUBVERSIÓN DEL ORDEN EN LA CISMA DE INGALATERRA
}

\author{
Lavinia Barone \\ Dipartimento di Letterature e culture europee (DILCE) \\ Facoltà di Lettere e Filosofia \\ Università degli Studi di Palermo \\ Via delle Scienze. Edificio 12 \\ 90128 Palermo. Italia \\ laviniabarone@gmail.com
}

[Anuario calderoniano (ISSN: 1888-8046), 4, 2011, pp. 17-32]

Dentro de la representación teatral destaca un sistema heterogéneo de signos que actúan a diferentes niveles y cuya combinación determina la construcción del sentido de la obra. Vamos a analizar el disfraz de la locura en La cisma de Ingalaterra a la luz de su carácter de signo escénico, cuya acción se despliega en los niveles visual, verbal y mímico-gestual ${ }^{1}$. Ya veremos cómo no se trata sólo de un elemento concreto de la puesta en escena, envuelto en la connotación del per-

${ }^{1}$ Debido a la imposibilidad de ofrecer aquí un aparato crítico exhaustivo relativo a las referencias bibliográficas sobre el asunto teórico del signo teatral, me limito a indicar los trabajos clásicos de Kowzan, 1968 y 1975. 
sonaje de Pasquín y que contribuye a su caracterización, sino también de la que se puede considerar una metáfora dramática de la subversión del orden establecido y del desenmascaramiento de la ficción, una figura que actúa a un nivel macrotextual, penetrando en todas las dimensiones de este drama calderoniano.

Como es sabido, el empleo del vestuario en el teatro áureo español se asentaba sobre unos principios convencionales, de manera que el espectador pudiera identificar en seguida al personaje gracias a la inmediata efectividad visual ${ }^{2}$. La relación entre vestuario y papel se establece a partir del significado social del traje que sugiere al espectador unas informaciones que le permitirán deducir su comportamiento durante la representación y, además, esbozar un perfil de su papel. Estas informaciones contribuyen, por lo tanto, a construir la identidad del personaje a través de las funciones simbólicas del vestuario, de manera que con sólo ver al actor, ya adivinamos su sexo, edad, posición social, raza y nacionalidad, la posible pertenencia a unos tipos folclóricos o dramáticos, su profesión y, finalmente la época en la que se desarrolla la acción ${ }^{3}$.

El asunto del vestuario teatral, además, fue contemplado por los tratadistas de la época como un precepto fundamental dentro de la creación dramática, cuyo empleo en la representación escénica tenía que encajar en la realización de lo verosímil poético. Sin hacer hincapié en todos ellos, cabe mencionar a Pellicer de Tovar que, en el Precepto 171 de su Idea de la Comedia de Castilla de 1635 afirmaba:

la gala y el adorno en los que la representan es elocuencia muda que escuchan los ojos. Para lo cual necesita de acomodarse a los trajes de las naciones donde introduce el suceso; si es en Francia, Inglaterra, Roma, España, Turquía o la India Occidental y Oriental cuidar de advertir a los autores los usos de aquellas provincias según el tiempo de que escribe ${ }^{4}$.

${ }^{2}$ Sobre los sentidos y las funciones de este complejo recurso escénico, ver De los Reyes Peña, 2000, y Navarro de Zuvillaga, 1996.

3 Sobre las diferentes teorías que interpretan la vestimenta como un sistema de signos ver Juárez Almendros, 2006, pp. 26-40.

${ }^{4}$ Pellicer de Tovar, Idea de la Comedia de Castilla deducida de las obras cómicas del Doctor Juan Pérez de Montalbán, citado en Sánchez Escribano y Porqueras Mayo, 1972, p. 271. 
El mismo asunto fue teorizado también por Alonso López Pinciano en la Epístola XIII de su Filosofía antigua poética donde, después de definir el ornato como «la compostura del teatro y de la persona y, además, aquel movimiento que hace el actor con el cuerpo, pies, brazos, ojos y boca cuando habla, y aun cuando calla algunas veces», prosigue aplicando el principio del decorum también al vestuario. De hecho, él afirma que

en la persona, después de considerado el estado, se debe considerar la edad, porque claro está que otro ornato y atavío o vestido conviene al príncipe que al siervo, y otro al mozo que al anciano; para lo cual es muy importante la segunda consideración del tiempo, porque un ornato y atavío pide ahora la España y diferente el de ahora mil años [...]; asímismo se debe tener noticia de las regiones, que en cada una suele haber uso diferente de vestir 5 .

Es evidente, entonces, que uno de los principios teóricos más defendidos por los preceptistas de la época es justo el del decorum, cuyo fundamento está constituido por la concordancia absoluta y la congruencia entre el personaje y su manera de expresarse, ya sea ésa a través del lenguaje o de la acción y de su aspecto sobre los escenarios. El carácter simbólico y convencional del vestuario, que el público de la época estaba acostumbrado a descifrar y reconocer rápidamente, adquiría entonces un papel muy importante ya que su valor semántico y connotativo alcanzaba compensar las carencias del decorado empleado en el corral. Como destaca precisamente José M. Díez Borque, «el código del vestuario puede ser estudiado en dos planos distintos: en su manifestación lingüística (acotaciones escénicas) y en su manifestación efectiva-visual (los signos tal y como aparecen materializados en escena») $)^{6}$. Una de las referencias más imprescindibles para conocer las características del vestuario en el teatro del Siglo se Oro está constituida por las acotaciones, en las que la descripción del mismo puede oscilar entre la abundacia de detalles y las indicaciones más genéricas. Además, gracias al mecanismo de la redundancia, es posible sacar más informaciones sobre las características del vestuario y

5 Cito de acuerdo con López Pinciano, Filosofía antigua poética, ed. A. Carballo Picaro, 1953, vol. III, pp. 277-278.

${ }^{6}$ Díez Borque, 1975, p. 68. 
sus funciones de las referencias que se vayan encontrando en los parlamentos de los personajes dentro del texto de la obra ${ }^{7}$. Si asumimos que «la ambigüedad del código de la ropa, su calidad de ser transferible y su índole teatral ofrecen ricas posibilidades tanto para establecer la identidad como para ocultarla o transformarla» ${ }^{8}$, veremos en qué manera, si por un lado el vestirse determina una adquisición de identidad gracias a las funciones simbólicas que conlleva el traje, por el otro el recurso escénico del disfraz resulta ser funcional respecto al desarrollo de la acción y, además, implica una reflexión sobre el mismo concepto de identidad del personaje, ya que ésta no sólo puede sustentarse del principio de la ficción, sino también del recurso al enmascaramiento o a la ocultación de la misma identidad. Por eso, lo que es menester descifrar es el sentido y las razones de dicha ficción, es decir, su exacta función dentro del fenómeno de la representación ${ }^{9}$. El mecanismo de identificación que se produce a través del recurso escénico al vestuario y al disfraz adquiere sentidos aún más interesantes cuando funciona como elemento connotativo de personajes cómicos o ridículos (entre los que, en primera instancia, incluiríamos a Pasquín, por su papel de bufón en la corte de Enrique VIII), sobre todo por no respetar éstos las normas que rigen el principio dramático del decorum al que acabamos de referirnos. Hay que subrayar cómo a la caracterización del vestuario destinado a aquellas figuras teatrales que pertenecen a la esfera de la comicidad, contribuye la herencia cultural constituida por la dimensión de la antropología carnavalesca que siglos de tradición popular han codificado a través de rasgos simbólicos constantes y bien reconocibles. Dentro de los mecanismos que rigen la construcción del aspecto de dichos personajes, destacan sobre todo la estereotipación, la degradación ridícula, el recurso a todos los matices posibles de la forma desproporcionada y, finalmente, la manipulación grotesca del cuerpo y de sus diferentes modalidades expresivas $^{10}$.

7 Sobre el mecanismo de la redundancia en el sistema de la comunicación teatral, ver Elam, 1980, pp. 43-44.

${ }^{8}$ Juárez Almendros, 2006, p. 30.

${ }^{9}$ Fischer-Lichte, 1999, pp. 136-143.

10 Sigue representando una referencia fundamental el trabajo crítico de Bachtin (1975) sobre la cultura cómica popular. Su análisis sobre las formas de la comunica- 
En lo que se refiere a La cisma de Ingalaterra, el aspecto bufonesco de Pasquín, cuyo componente más llamativo es el vestido ridículo con el que sale al escenario, actúa como signo teatral de múltiples sentidos porque traduce, no sólo visualmente, una locura ficticia que podemos definir como un disfraz (ya que no tiene un origen patológico y, por lo tanto, no es una enfermedad mental), sino también a nivel de la expresión verbal y mímico-gestual, hasta llegar a representar una macrometáfora textual que se desarrolla a lo largo de todo el drama. Puesto que no es este el lugar para analizar detalladamente el complejo asunto cultural y social de la locura dentro de la larga tradición literaria del Renacimiento y del Barroco europeos, nos conformamos con unas referencia esenciales, útiles para la introducción de nuestro análisis del personaje de Pasquín.

Orígenes, razones y modalidades expresivas de la locura destacan dentro de la llamada «literatura del loco» que se afirma en su periodo clásico en los siglos XV-XVII ${ }^{11}$. El apogeo de las reflexiones literarias sobre dicho tema se produce sobre todo con la aparición de obras como la Narrenschiff de Sebastián Brant de 1494 y la Stultitiae Laus de Erasmo de Rotterdam en $1508^{12}$.

Además, cabe mencionar la naturaleza polimórfica del fenómeno de la locura así como fue considerado a lo largo de la Edad Media hasta el siglo XvII, ya que en su caracterización solían confluir normalmente tanto la dimensión patológica, cuanto aquella relativa a la ficción, a la espectacularización y a la ritualización. Este carácter híbrido de la locura se manifiesta a través de un conjunto de signos codificados por la tradición y generalmente reconocidos gracias a su valor simbólico. Uno de los recursos más utilizados para sacar más detalles sobre la iconografia del loco es el análisis de los naipes de esta figura en los tarots, el estudio de las miniaturas de la Edad Media y, por supuesto, la Iconología de Cesare Ripa ${ }^{13}$. Sin detenernos demasiado en la descripción detallada de todas estas fuentes, nos fijamos en esos ele-

ción verbal y mímico-gestual subraya los mecanismos que producen la subversión de los valores convencionales a través de recursos como la inversión y la parodía que además alimentan el concepto estético del «realismo grotesco».

11 Nos limitamos a indicar unos títulos esenciales sobre este asunto: Márquez Villanueva, 1985-1986; Swain, 1932; Foucault, 1961.

12 Ver Schwartz Lerner, 1985.

${ }^{13}$ Ver Atienza, 2009, pp. 17-25. 
mentos más frecuentes y llamativos que, en el imaginario colectivo, se remontaban a la idea de la deformidad fisica y moral, expresadas visualmente por medio de unos rasgos que convertían al loco en un ser fuera de lo común, en algo inusual por su imperfección, lo que por supuesto le alejaba de toda idea de armonía y equilibrio, es decir de esas normas que Dios había concedido al mundo para garantizar su orden. La desnudez se acompaña generalmente a la ostentación de toda bajeza, materialidad y sensualidad de la vida, es decir, de esa dimensión de la existencia de la que el loco es condiderado un símbolo. La expresión de su cara puede oscilar entre la sonrisa y el rostro melancólico y a menudo destaca en su imagen codificada la presencia de objetos sobre su cabeza como cascabeles, plumas o el gorro puntiagudo, así como la inserción de su atributo simbólico, un bastón que lleva encima un espejo o una rueda de papel. Asimismo, también el elemento cromático solía poner de relieve el desorden y la sinrazón, ya que éstos se podían expresar a nivel visual a través del recurso de la abundancia de trapos de colores en la ropa ${ }^{14}$. En resumidas cuentas, hemos comprobado que en la identidad híbrida del loco solían confluir por un lado la deformidad mental o fisica, por el otro la actitud hacia el artificio y la simulación y, finalmente, un conjunto de signos codificados que pertenecían a la iconografía tradicional de la antropología carnavalesca. Un ejemplo de lo que acabamos de afirmar se encuentra en la definición del término loco que Sebastián de Covarrubias y Horozco propuso en su Tesoro de la lengua castellana o española de 1611, en la que destacan sobre todo dos de las posibles etimologías que, según el lexicógrafo, podían explicar el origen oscuro de una palabra que «tornará loco a qualquier hombre cuerdo». Entre las hipótesis hechas por Covarrubias, mencionamos primero la que se remonta a la palabra latina locus, «por el lugar, atento que al loco solemos llamar vacío y sin seso», y luego la que busca el origen en la

${ }^{14} \mathrm{La}$ variedad de los colores y el simbolismo que se acompaña a ésta, se pueden relacionar, por ejemplo, con la tradición teatral del vestuario que caracteriza al personaje de Arlequín, una de las máscaras principales de los Zanni de la Commedia dell'Arte italiana. Para un examen más profundo del asunto se remite a Fiorini, 2002, pp. 52-57. 
locución «a luce, per contrarium sensum, por habérsele ofuscado y entenebrecido el entendimiento» ${ }^{15}$.

Hacia esta identidad compleja que hemos definido como híbrida, se manifiestan dos tendencias: una escoge el aislamiento de estas figuras marginales de la sociedad, por constituir el símbolo de un desorden que amenaza la armonía del universo, y la otra, en cambio, las transforma en seres privilegiados que disfrutan de una libertad de expresión inusual y de cierta impunidad jurídica y moral por no ser conscientes ni responsables de su comportamiento. Simulada o real, la locura de estas figuras se trasforma en llave de acceso a los palacios de los poderosos que acogen tanto a los locos auténticos como a los truhanes, para entregarles el oficio de la risa y consacrarles como bufones. Su presencia entre los poderosos se explica si consideramos que "como en un juego de espejos, estos seres descomunales, faltos o excesivos, afirman en los otros la normalidad que su cuerpo o su mente están negando. Con su descompostura son, involuntariamente, símbolos, emblemas, anagramas de la perfección de que carecen y que, sin embargo, adorna a los "meliores terrae», reyes, nobles y cortesanos que, a su lado, parecen aún más majestuosos y pulidos» ${ }^{16}$.

La codificación convencional de la locura, reconocible entonces por unos signos inequívocos, constituye cierto repertorio muy rico no sólo para quienes anhelen la nómina de sabandijas de palacio, sino también para esos dramaturgos y letrados que quisieran colocar en sus obras una figura tan emblemática como la del loco. Tal y como afirma Martine Bigeard, «sous la Renaissance, la façon de jouer le rôle du fou n'était pas laissée au hazard; elle obéissait à des conventiosns fixées depuis le moyen âge, connues de toutes les troupes, si bien qu'il suffisait à l'auteur de noter à propos d'un personnage: "entrée de... en fou", pour que les comédiens sachent aussitôt à quoi s'en tenir» ${ }^{17}$. Ya veremos en qué manera la locura actúa, en La cisma de Ingalaterra, como signo escénico doble, es decir por un lado como disfraz del personaje de Pasquín, que se va caracterizando a lo largo de la acción como doble paródico de la figura del rey a través de paralelismos y

15 Cito de acuerdo con Sebastián de Covarrubias y Horozco, Tesoro de la lengua castellana o española, ed. I. Arellano y R. Zafra, 2006, p. 1210.

16 Bouza, 1991, p. 20.

17 Bigeard, 1972, p. 80. 
analogías (tanto al nivel de lenguaje verbal como al del lenguaje escénico) y, por el otro, como símbolo paradigmático de la subversión del orden, lo que resulta realmente el motor de la acción, y cuyo representante terrenal es justo el mismo soberano. Es imprescindible empezar desde la escéna inicial del drama, ya que ahí la representación del sueño de Enrique VIII adquiere múltiples sentidos ${ }^{18}$.

REY Tente, sombra divina, imagen bella, sol eclipsado, deslucida estrella.

Mira que al sol ofendes cuando borrar tanto esplendor pretendes. ¿Por qué contra mi pecho airada vives?

AnA Yo tengo de borrar cuanto tú escribes.

Vase.

Rey Aguarda, escucha, espera.

No desvanezcas en veloz esfera esa deidad tan presto $^{19}$. (vv. 1-9)

A pesar de que, según la moral cristiana, el fiel no debía confiar ni creer en el poder premonitorio de los sueños y de los presagios (y ya veremos que ésta es justo la mayor locura que se atribuye a Pasquín), cuando quienes los tenían eran unas figuras muy importantes como los reyes (o sea, los detentores terrenales del poder divino), entonces se consideraban como unos signos del cielo de los que se había de tener en cuenta. Además, esta actitud adivinatoria constituye una de las analogías entre el personaje de Enrique VIII y el del gracioso, y está relacionada por medio de unos elementos que a continuación vamos a analizar. Si nos detenemos en el sueño del soberano, veremos como en éste encontramos por un lado la metáfora astronómica de la puesta de las estrellas y la redundancia del mismo campo semántico y, por el otro, unas referencias a la belleza de Ana Bolena que nos permiten individuarlas en las palabras de Pasquín (vv. 613-632). La hermosura de la mujer que aparece en el sueño del rey es traducida por las imá-

${ }^{18}$ Ver la introducción a Calderón de la Barca, La cisma de Ing[a]laterra, ed. Ruiz Ramón, pp. 7-13.

${ }^{19}$ A partir de ahora, nos referimos al texto de La cisma de Ingalaterra según la edición de Escudero, 2001. 
genes de un «sol eclipsado» y de una «deslucida estrella», que anticipa su caída y, junto a la alusión a su presunción, también su actitud destructora y los peligros que la misma conlleva. Además, la imagen del sol, cuya luz la belleza de esa "deslucida estrella» pretende borrar, nos remite a la metafora clásica del poder ${ }^{20}$, que en este caso puede aludir tanto al soberano enloquecido por amor, como a la ley de Dios que Ana Bolena - junto al cardenal Volseo- perjudicará al empujar el reino de Inglaterra hacia las tinieblas y el caos de la cisma, a través del divorcio del rey de su legítima mujer. En lo que se refiere a la consiguente subversión del orden y de los valores que éste conlleva, Calderón utiliza unos recursos escénicos basados en el principio de la inversión, empezando por la imagen de la mujer que con la mano izquierda borra lo que el rey acaba de escribir con la derecha, símbolo de la verdad (vv. 114-116), pasando por la equivocación de las cartas —una de León Décimo y la otra de Martín Lutero- (vv. 145-167) y, finalmente, por la boda ilegítima con Ana Bolena tras repudiar a Catalina (vv. 1663-1665), lo que determina el alejamiento de la doctrina católica y la elección a favor del luteranismo. Si tenemos en cuenta que el rey es quien garantiza en el mundo el orden divino, por la correspondencia entre el macrocosmo del universo y el microcosmo humano de los gobiernos, la locura de Enrique, cuyo doble paródico es justo el gracioso Pasquín, y cuyas consecuencias afectan tanto al reyno como a su familia (que además representa el fundamento de la Iglesia), determina la corrupción de dicho orden y de la justicia terrenal.

Aunque no podemos identificar al gracioso como el héroe trágico de este drama calderoniano, cuyo protagonismo pertenece en cambio a la figura del rey, sí podemos subrayar esos elementos de su actuación dramática, como el comportamiento desmedido en relación con la normas vigentse que rigen la organización de la realidad, que evidencian su papel trágico, lejos de la caracterización convencional del bufón ${ }^{21}$. A pesar de las polémicas literarias y de los preceptos dramáticos de los tratadistas más rigurosos, la mezcla de elementos serios y cómicos en la misma obra se iba asentando cada vez más como una convención teatral reconocida y aceptada. Además, la inserción de ele-

${ }^{20}$ Ver Díaz Armas, 2002.

${ }^{21}$ Ver Cancelliere, 2003, pp. 129-130. 
mentos risibles en obras trágicas se caracterizaba por la tendencia a la marginalización y la pérdida de los rasgos cómicos de los personajes graciosos. La realización escénica de este fenómeno se puede averiguar en la actuación de Pasquín, cuya inserción en una acción trágica y cuyo papel de denunciador le impiden mantener la típica capacidad risible de los bufones y le convierten en un personaje serio, aunque la gravedad de su función dramática contrasta con su apariencia ridícula. La marginalización del gracioso suele manifestarse en la escéna a través de su expulsión o rechazo: en efecto, Volseo intenta alejarle del rey y los demás le consideran un loco sin importancia, así que Pasquín saldrá del escenario de repente poco antes de que se acabe el drama. El valor de su papel no radica - como afirma Arellano- en su vertiente ideológica, ya que no rechaza el poder del soberano ni su centralidad, sino que se manifiesta a nivel moral contra las vanidades y la hipocresía de los personajes que intentan destruir un sistema que ha de ser mantenido ${ }^{22}$.

Calderón dramatiza, a lo largo de la obra, la caída de Enrique VIII hacia la sinrazón, debida a su peligrosa pasión por Ana, poniendo de relieve cómo el rey se ha ido enloqueciendo a pesar de su ingenio y aún siendo un hombre docto, "tan celebrado, / tan prudente y advertido» (vv. 267-268), defensor de la cristianidad y esposo fiel de «la más hermosa y católica reina / que tuvieron los ingleses» (vv. 27-28). Tal y como el rey intenta ocultar su falta de juicio, incluso empujado por los malos consejos y las disimulaciones de Volseo y Ana, el personaje de Pasquín fundamenta toda su actuación y la construcción de su carácter sobre el principio de una locura fingida, cuyas raíces se remontan a la figura emblemática del loco cuerdo y a la del ciego vidente, lo que no sólo cabe dentro de la tradición del fou sage, sino que nos recuerda a la figura del adivino griego Tiresias. En lo que se refiere primero a la sabiduria de Pasquín, el carácter ficticio de su locura queda definido a través de sus mismos parlamentos, donde encontramos también la justificación moral de esta ficción, ya que le permite al gracioso afirmar aquellas verdades incómodas cuyo desvelo no puede dejar impune sino a los que están reconocidos $\operatorname{como} \operatorname{locos}^{23}$. Además, merece la pena detenernos un momento en la analogía entre nuestro

22 Arellano, 2006, pp. 48-52.

${ }^{23}$ Ver Ruiz Ramón, 2005, pp. 212-214. 
personaje y la figura del adivino Tiresias de la mitología clásica ${ }^{24}$, ya que su ceguera, sus capacidades divinatorias y sus relaciones con los poderosos ${ }^{25}$ nos recuerdan mucho las del mismo Pasquín. En el imaginario tradicional, el adivino posee unas características que le permiten destacar entre los hombres comunes, y la ceguera cabe dentro de éstas ya que, tal y como la de los poetas, representa un símbolo de su sabiduría y constituye un signo de su capacidad de adivinización, según una lógica que compensa cada minoración fisica con alguna cualidad extraordinaria ${ }^{26}$. Aunque la ceguera del gracioso no sea real, tiene un sentido metafórico que expresa la capacidad de este personaje de actuar como una guía para los demás, siendo la luz que lleva un instrumento que le sirve para alumbrar la verdad y aconsejar a los que le rodean (vv. 573-601).

La llamativa aparición de Pasquín en el escenario que, como se ha dicho antes, está caracterizada por el vestuario ridículo, se acompaña de las referencias sobre su figura hechas por Dionís y Carlos, que lo definen como loco y truhán. El mismo Pasquín enfatiza su aspecto ridículo al definirse "galán de los galanes» (v. 473). Según Covarrubias, el galán es «el que va vestido de gala» ${ }^{27}$, es decir un "vestido curioso y de fiesta, alegre y de regocijo» ${ }^{28}$. Dentro de la caracterización dramática de Pasquín, hay que fijarse en la oposición entre la forma ridícula, que en la escena está representada por su vestido y por la actuación bufonesca, y el sentido grave de sus palabras que acompañan a su importante función de doble del rey. La locura fingida de Pasquín resalta la pérdida de juicio de Enrique VIII por ser el recurso paradójico que el gracioso elige para desenmascarar las ficciones de los demás, aún quedándose entre ellos, ya que — como él mismo afirma«un loco más o menos / poco les puede estorbar» (vv. 487-488). Por

24 Sobre este personaje, ver Brisson, 1976 y Di Rocco, 2007.

25 Entre ellos, recordamos en primer lugar al rey Edipo, protagonista de la tragedia omónima de Sófocles, quien preguntó al adivino la identidad del hombre que mató a su padre y al que Tiresias reveló no sólo ser él mismo, sino también que al acabarse el día el culpable se iría de la ciudad ciego y mendigo. Asimismo, el héroe Odiseo, bajo el consejo de Circe, se fue al reino de los muertos al fin de hablar con Tiresias para pedirle unos consejos que le ayudarían a volver a Ítaca (Odisea, XI).

${ }^{26}$ Ver Napolitano Valditara, 2004.

27 Tesoro de la lengua castellana o española, p. 943.

28 Tesoro de la lengua castellana o española, p. 943. 
eso afirmamos que la función desvalorizadora de su aspecto ridículo, junto al papel ficticio de loco y truhán, se opone al sentido más profundo de su discurso y de su actuación, mientras que su lenguaje y su función de doble paródico de Enrique denuncian el dualismo y las contradicciones de la realidad ${ }^{29}$. Dicha voluntad desenmascaradora de Pasquín se expresa no sólo por medio del disfraz de la locura, lo que cabe dentro de la figura de bufón de corte, sino también a través de la ironía de su lenguaje y de la solicitud del cargo, aparentemente risible, de «denunciador de figuras». En lo que se refiere al discurso irónico, es evidente que se trata de un recurso retórico basado sobre la misma inversión del sentido de las palabras, lo que puede llevar a la paradoja y a la ambigüedad. De la misma manera, el uso del término figura es fundamental por el sentido que conlleva, ya que su origen se remonta al verbo latín fingo, «mox generale fit vocabulum ad caetera, quae ingenio, manuque hominis artificiose formantur, aut simulantur ${ }^{30}$, y expresa el acto de fingir y de cambiar algo su forma, incluso a través de algún disfraz.Y precisamente gracias a este «cargo figurífero» (v. 1674), Pasquín denunciará el desdoblamiento de Enrique VIII, cuya locura le hace actuar como quien ha perdido el juicio, pero sigue siendo disimulada bajo toda aparencia de sabiduría que, junto a Calderón, diríamos que vigilante a los errores se opone. Si nos fijamos en la profecia de Pasquín, veremos cómo el objeto de la misma — es decir, Ana Bolena - coincide con la sombra del sueño del rey, y su identificación es posible gracias a las referencias a la belleza peligrosa de la mujer y a la parábola de su subida y caída, que nos recuerda la imagen del sol eclipsado de la escena primera. El turbamento inicial del rey, debido al sueño y al haber trocado las cartas (ambos hechos intrepretados por él mismo como presagios), se hace mayor en cuanto encuentra por primera vez a Ana Bolena, lo que primero determina su asombro por reconocer en el rostro de la mujer el mismo que le apareció en el sueño, y luego causa su enamoramiento fatal por ver en ella el "prodigio humano» (vv. 850-868) de la belleza.

Empezando por unas referencias al sueño del acto I, todo el segundo desarrolla el tema del enloquecimiento de Enrique VIII y de su tristeza, hasta manifestar por un lado como Volseo y la misma Ana

${ }^{29}$ Ver La cisma de Ing[a]laterra, ed. Ruiz Ramón, pp. 20-21.

30 Novus Linguae et Eruditionis Romamae Thesaurus, vol. I, p. 666. 
actúan aprovechándose de ese turbamento, y por el otro cómo el comportamiento de ambos se asenta sobre una precisa elección a favor de la ficción.

A medida que avanzan la locura y las sinrazones del rey, las palabras de Pasquín, a pesar de ser consideradas como disparates por los demás, adquieren en cambio un sentido cada vez más grave y serio para los espectadores, quienes conocen las trampas, las pasiones y los sentimientos verdaderos de los personajes y pueden interpretar correctamente el mensaje del gracioso. Esta sabiduría de Pasquín se transmite, a nivel de la expresión verbal, a través de recursos como los cuentecillos tradicionales ${ }^{31}$. Además del que ya comentamos, también el segundo se refiere al filósofo griego Diógenes y le sirve al gracioso para subrayar la inutilidad de todo poder e ingenio para aliviar el dolor y remediar la pérdida del juicio que afectan al rey, ya que se trata de los efectos de la subversión de aquel orden divino que el mismo soberano no ha sido capaz de tutelar (vv. 936-966).

También en el acto III, dentro del discurso dramático de Pasquín se inserta otro cuentecillo más sobre la construcción del sepulcro de Volseo. Su forma de dicho gracioso - y como disparate efectivamente es interpretado por ése- recurre a la imagen de una jaula demasiado grande para acoger a un pajaro muy pequeño ${ }^{32}$, es decir, que la presunción del cardenal y sus proyectos, además de estar destinados al fracaso, le llavarán a un final trágico de pobreza y ceguera, no metafórica como la de Pasquín, que se ha apartado de la vista engañosa de la realidad para confiar sólo en la luz del entendimiento, sino verdadera y simbólica al mismo tiempo, ya que representa la punición por su actos malvados (vv. 2347-2348).

Pasquín saldrá del escenario dentro de poco, a mitad del acto III, tras aconsejar al rey que se guarde de Volseo puesto que éste le podría desterrar de su reino tal y como le prohibió al gracioso que volviera al palacio. Es el momento en el que por fin Enrique VIII recobra la razón: al despertar de su sueño, todos los agüeros que le habían asombrado ya son realidad. Es el inicio de la caída del cardenal, ya que a las alusiones ambiguas de Pasquín se añaden en seguida las quejas

31 Siguen siendo unas referencias fundamentales sobre este tema los trabajos ya clásicos de Chevalier, 1983 y 1995.

${ }^{32}$ Ver Chevalier, 1983, pp. 292-293. 
de los soldados, y es además el final de la presencia del bufón en el escenario. Seguirán la muerte de la reina Catalina, el destierro de Volseo, el asesinato de Ana Bolena por orden del rey y la tentativa del mismo de corregir los efectos funestos de su locura que ha sido la causa verdadera de la subversión del orden, empujada por las trampas de los malvados y alimentada por el índole débil del «docto ignorante» Enrique que ha perdido el juicio y se ha rendido a la pasión, alejando tanto su vida como el destino del reino de la ley de Dios. 
BIBLIOGRAFÍA

Arellano, I., Convención y recepción. Estudios sobre el teatro del Siglo de Oro, Madrid, Gredos, 1999.

- El escenario cósmico. Estudios sobre la comedia de Calderón, Madrid / Frankfurt, Iberoamericana / Vervuert, 2006.

Atienza, B., El loco en el espejo. Locura y melancolía en la España de Lope de Vega, Amsterdam / New York, Rodopi, 2009.

Bachtin, M., L'oeuvre de François Rabelais et la culture populaire au Moyen Âge et sous la Renaissance, Paris, Gallimard, 1970.

Bigeard, M., La folie et les fous littéraires en Espagne, 1500-1650, Paris, Centre de Recherches Hispaniques, 1972.

Bouza, F., Locos, enanos y hombres de placer en la corte de los Austrias, Madrid, Ediciones Temas de Hoy, 1991.

Brisson, L., Le mythe de Tirésias. Essai d'analyse structurale, Leiden, Brill, 1976.

Calderón de la Barca, P., La cisma de Ing[a]laterra, ed. de F. Ruiz Ramón, Madrid, Castalia, 1981.

- La cisma de Ingalaterra, ed. J. M. Escudero, Kassel, Reichenberger, 2001.

Cancelliere, E., «Dos tipos de locura: la rebelión de Segismundo y la obediencia de don Fernando", Criticón, 87-89, 2003, pp. 129-142.

Chevalier, M., Cuentos folklóricos en la España del Siglo de Oro, Barcelona, Crítica, 1983.

- «Cuento tradicional y literatura del Siglo de Oro», en Culturas en la Edad de Oro, ed. J. M. ${ }^{a}$ Díez Borque, Madrid, Editorial Complutense, 1995, pp. 113-122.

Covarrubias y Horozco, S., Tesoro de la lengua castellana o española, ed. I. Arellano y R. Zafra, Madrid / Frankfurt, Iberoamericana / Vervuert, 2006.

De los Reyes Peña, M. (dir.), El vestuario en el teatro español del Siglo de Oro, Cuadernos de Teatro Clásico 13-14, Madrid, Compañía Nacional de Teatro Clásico, 2000.

Díaz Armas, J., «El Sol como metáfora del Príncipe», en Calderón 2000: homenaje a Kurt Reichenberger en su 80 cumpleaños. Actas del Congreso Internacional, IV centenario del nacimiento de Calderón, ed. I. Arellano, Kassel, Reichenberger, 2002, vol. I, pp. 427-446.

Díez Borque, J. M. ${ }^{a}$, "Aproximación a la escena del teatro del Siglo de Oro», en Semiología del teatro, ed. J. M. Díez Borque y L. García Lorenzo, Barcelona, Planeta, 1975, pp. 50-92.

Di Rocco, E., Io Tiresia: metamorfosi di un profeta, Roma, Editori Riuniti, 2007. Elam, K., The Semiotics of Theatre and Drama, New York, Methuen, 1980.

Falcón Martínez, C., Diccionario de Mitología Clásica, Madrid, Alianza, 1985.

Fiorini, C., Maschere italiane, Firenze, Giunti Editore, 2002.

Fischer-Lichte, E., Semiótica del teatro, Madrid, Arco Libros, 1999. 
Foucault, M., Histoire de la folie à l'âge classique, Paris, Plon, 1961.

JuÁrez Almendros, E., El cuerpo vestido y la construcción de la identidad en las narrativas autobiográficas del Siglo de Oro, London, Tamesis, 2006.

Kowzan, T., «The sign in the theatre: an introduction to the semiology of the art of the spectacle», Diogenes, 61, 1968, pp. 52-80.

- Littérature et spectacle, Paris, Mouton, 1975.

López Pinciano, A., Filosofía antigua poética, ed. A. Carballo Picaro, Madrid, CSIC, 1953.

Márquez Villanueva, F., "Literatura bufonesca o del 'loco'», Nueva Revista de Filología Hispánica, 34, 2, 1985-1986, pp. 501-528.

Matthias Gesner, J., Novus Linguae et Eruditionis Romamae Thesaurus, Napoli, La Scuola di Pitagora Editrice, 2006, vol. 1.

Napolitano Valditara, L., Lo sguardo nel buio. Metafore visive e forme greco antiche della razionalità, Bari / Roma, Laterza, 2004.

Navarro de Zuvillaga, J., «De la tapada al desnudo (el vestuario como signo escénico en el teatro español)", en En torno al teatro del Siglo de Oro, Actas de las jornadas XII-XIII celebradas en Almería, ed. J. Berbel, H. Castellón, A. Orejudo y A. Serrano, Almería, Instituto de Estudios Almerienses / Diputación de Almería, 1996, pp. 123-146.

Ruiz RAmón F., «La figura del donaire como figura de mediación (El bufón calderoniano)» en La construcción de un personaje: el gracioso, ed. L. García Lorenzo, Madrid, Fundamentos, 2005, pp. 203-224.

Sánchez Escribano, F. y Porqueras Mayo, A. (eds.), Preceptiva dramática Española, Madrid, Gredos, 1972.

SCHWARTZ LERNER, L., "Discurso paremiológico y discurso satírico: de la locura y sus interpretaciones», Filología, 20, 2, 1985, pp. 51-78.

Swain, B., Fools and folly during the Middle Ages and the Renaissance, New York, Columbia University Press, 1932. 